\title{
A NAÇÃO CORDIAL \\ Uma análise dos rituais e das ideologias oficiais de "comemoração dos 500 anos do Brasil"*
}

\author{
Kelly Cristiane da Silva
}

As condições de colonização portuguesa [...] na Ásia, como no Brasil, nas ilhas do Atlântico e até certo ponto na África, desenvolveram nos bomens as mesmas qualidades essenciais de cordialidade e simpatia, características do povo português - o mais cristão dos colonizadores modernos nas suas relações com as gentes consideradas inferiores [...].

Gilberto Freire, O mundo que o português criou, 1940.

O objetivo deste texto é analisar as atividades promovidas pelo Estado brasileiro para celebrar aquilo que entre os anos de 1998 e 2000 foi

* Este texto foi originalmente formulado como trabalho final para a disciplina Seminário Avançado em Teoria, conduzida por Mariza Peirano no segundo semestre de 2000 no Programa de Pós-Graduação em Antropologia Social da Universidade de Brasília. Agradeço às sugestões apresentadas por ela, bem como às leituras críticas de Luís Roberto Cardoso de Oliveira, Alcida Rita Ramos e Daniel S. Simião.

Artigo recebido em junho/2001.

Aprovado em maio/2002. por ele denominado "500 anos de descobrimento do Brasil". Fazendo uso de narrativas e de documentos oficiais a respeito das atividades que, em conjunto, conformaram esse evento de "comemoração", busco mapear as ideologias ${ }^{1}$ afirmadas por meio dele, bem como a imagem de nação apresentada, pressupondo serem essas festividades momentos exemplares do processo de nationbuilding (Bendix, 1977; Elias, 1972) brasileiro. Procuro abordar esses acontecimentos como um único evento ritual, com diferentes fases e faces de manifestação. Para tanto, inspiro-me na abordagem performativa e semiótica que Tambiah (1985) utiliza para compreender os rituais. ${ }^{2}$

É preciso considerar que as ideologias oficiais a respeito dos "500 anos de descobrimento"3 foram produzidas em um contexto específico, num diálogo constante com outros atores sociais, dos quais destacam-se a mídia, as universidades, o mercado editorial, a sociedade ci- 
vil organizada e a comunidade internacional. Assim, embora esse texto enfoque principalmente as narrativas oficiais, explorarei, na medida do possível, o papel desempenhado por esses outros atores na conformação da ideologia estatal sobre os "500 anos do Brasil", analisando-a como um conjunto de crenças e valores produzido, de certa forma, em múltiplos lugares (Kroskrity, 2000).

O Estado, a esse respeito, assume um papel singular (Trouillot, 1995): é, ao mesmo tempo, ator histórico, desempenhando um script próprio na performance dos eventos que fizeram parte das "comemorações dos 500 anos de descobrimento", e narrador dos processos que tornaram possível "celebrar" o aniversário da chegada dos portugueses ao país. Embora essa dupla posição de sujeito seja partilhada por todos os agentes sociais, seria inadequado desconsiderar o poder do Estado em momentos como esses. É ele, por exemplo, que define quais acontecimentos devem ser fixados na memória da nação como seus sinais diacríticos - definidos, entre outras coisas, pela institucionalização de feriados -, além de fornecer os padrões valorativos que devem informar a apreensão desses eventos.

Seguindo os preceitos de Durkheim (1983), suponho ser o Estado uma das principais fontes morais para a fundação e a organização das cosmologias de nosso tempo. Essa função é ainda mais acentuada quando se trata de formular ideologias a respeito do que é a nação. ${ }^{4}$ Nas "comemorações do descobrimento", responder às questões do que foi, é e será o Brasil transformou-se em tarefa cotidiana. Nessa empreitada, o Estado apresentou-se como protagonista, embora disputasse com outros atores sociais o conteúdo das narrativas a serem contadas. ${ }^{5}$

A discussão que se segue está organizada em três itens, além da conclusão. No primeiro, examino as estratégias simbólicas utilizadas por diferentes atores para tornar o 22 de abril uma data a ser comemorada. No segundo, analiso fragmentos dos eventos oficiais de "comemoração" a fim de mapear o que aparece como padrão ideológico. Por fim, exploro, de forma bastante inicial, alguns dos efeitos perlocucionários das narrativas apresentadas pelo Estado, sugerindo que, ao se apropriar desses efeitos, ele repõe idéias afirmadas em outros momentos.

\section{A produção dos "500 anos de descobri- mento" e a reinvenção do paraíso}

Ao analisar os calendários dos últimos anos, inclusive o de 2000, deparamo-nos com um fato interessante: a data de 22 de abril não tem o estatuto de feriado nacional e não é sequer citada em muitas agendas. O dia que lhe antecede, ao contrário, é um feriado que evoca uma multiplicidade de eventos: dia de Tiradentes, personagem construído como herói da inconfidência mineira após a proclamação da República; é, ainda, o dia em que se cultiva a memória da morte de Tancredo Neves, denominado o "herói da Nova República" e, por fim, o dia escolhido por Juscelino Kubitschek para a inauguração da nova capital do país em 1960, tornando-se, em função disso, a data comemorativa do aniversário da cidade. Em meio a tantos eventos a serem lembrados, há indícios de que o dia do "descobrimento do Brasil" tenha passado despercebido à memória pública nacional durante muito tempo. Nesse sentido, se, de fato como suponho, não havia uma tradição comemorativa em torno dessa data, era preciso criá-la. Diante disso, a mídia, representada pela Rede Globo de Televisão, teve papel fundamental. Ela, juntamente com outros atores sociais - o Estado, entre deles - literalmente produziu os "500 anos do Brasil" como fato e evento a ser lembrado, "comemorado" e vendido. ${ }^{6}$ A seguir, procuro apresentar algumas das estratégias adotadas pela emissora ${ }^{7}$ e, em seguida, aquelas empregadas pelo Estado para a construção simbólica dessa data. ${ }^{8}$

A Rede Globo de Televisão elaborou um programa específico para gerenciar as atividades desenvolvidas no âmbito das "celebrações" dos "500 anos do descobrimento": o Brasil 500. Acessando o site dessa emissora, é possível abrir várias páginas nas quais são apresentados os subprogramas que compõem o projeto Brasil 500, dos quais destacam-se Amigos da Escola e História do Brasil. Além disso, observa-se o que há de mais 
significativo nas atividades desenvolvidas pela emissora para produção do evento. Trata-se da contagem regressiva à chegada de 22 de abril de 2000 , inserida no interior da programação diária da Rede Globo e nos 28 relógios fixados por ela nas principais cidades do país. Esses relógios não só tinham um visor que marcava as horas, mas também um contador de dias digital, no qual se fazia a contagem regressiva à aproximação das "comemorações dos 500 anos do Brasil". Assim, tornou-se impossível à maioria dos cidadãos ignorar que no dia 22 de abril do ano 2000, comemorar-se-ia a "descoberta" do país.

O contato cotidiano, durante dois anos, com a frase "Faltam $x$ dias para a comemoração dos 500 anos do descobrimento do Brasil" - presente tanto nos spots transmitidos pela TV como nos relógios gigantescos espalhados pelo país - criou em torno dessa data uma série de expectativas e ideologias. Os spots e os relógios exerciam, segundo a classificação elaborada por Jakobson (1965), duas funções comunicativas principais, além da referencial: ${ }^{10} 1$ ) a fática, que sublinhava a continuidade da comunicação entre a emissora e o telespectador em relação ao evento referido; e 2) a metalingüística, que apresentava os termos valorativos sobre os quais a chegada dos portugueses deveria ser interpretada, qual seja, como "descobrimento" ta, fundação etc. ${ }^{12}$

Essas funções eram também exercidas por meio de outras estratégias. Vale lembrar que a Rede Globo exibiu duas miniséries em 2000 - $A$ muralha e Caramuru: a invenção do Brasil- cujos enredos abordavam a chegada e a fixação dos portugueses no continente americano. Além disso, a emissora produziu dez shows populares em metrópoles do país, que, retransmitidos em cadeia nacional, tinham como unidade simbólica a celebração dos "500 anos do Brasil". 13

Uma análise das atividades desenvolvidas pelo Ministério do Esporte e Turismo (MET) em função das "celebrações dos 500 anos" permitenos inferir que o cenário do apogeu das "comemorações" também foi construído ${ }^{14}$ porém, não mais pela Rede Globo, mas pelo próprio Estado. A fim de revitalizar a região em que o "Brasil nas- ceu", o MET elaborou o projeto Museu Aberto do Descobrimento (MADE), que destinou à região do extremo sul da Bahia - arredores de Porto Seguro - uma grande quantidade de recursos, aplicados na recuperação dos sítios históricos da região, bem como à construção de novos monumentos. Para se ter uma noção do que foi esse projeto, resgato a seguir uma de suas descrições, presente na home page Terra Brasilis: ${ }^{15}$

Se até aqui o que mais atraía os visitantes era a alegria contagiante, as belas praias e axé music que faz o corpo mexer mesmo sem muita ginga, agora é a história que se torna o principal ingrediente na fórmula do sucesso de Porto Seguro. Pelo menos neste ano, momento em que os olhos do país estão voltados para aquela que certamente será a maior festa do ano: a comemoração dos 500 anos do descobrimento.

[...] Proposta de museu natural, ao ar livre, a céu aberto, onde as galerias são praias, vales e trilhas naturais e o acervo, um conjunto de acidentes geográficos e núcleos urbanos tradicionais, dispostos como peças em exposição permanente, descritos em documentos antigos, distribuídos ao longo de $78 \mathrm{Km}$, em linha reta, do histórico litoral sul da Bahia [...] (http://www.500anos/portohtm.com.br).

Assim, fazem parte do Museu Aberto do Descobrimento acidentes naturais (Monte Paschoal, enseada de Porto Seguro, mangues etc.) e núcleos urbanos tradicionais. Ao se buscar o sentido do que seriam esses núcleos urbanos tradicionais, verifica-se que eles foram imaginados como os tipos de aglomerações populacionais existentes à época em que Cabral aportou na região, entre os quais destaca-se a aldeia indígena. ${ }^{16}$ Nesse sentido, era preciso que esse museu possuísse um exemplar de aldeia. Para tanto, as autoridades do governo federal demarcaram as terras Pataxó - povo que, nesses eventos, se autoapresentava como ocupante da região à época do descobrimento, obliterando a presença secular dos Tupinambá no sul da Bahia - e expulsaram as famílias não indígenas que ali viviam. ${ }^{17}$ No entanto, a investida em direção à separação dessas populações não se esgotou na demarcação das terras. Criaram-se também diferentes centros turísticos comerciais: um para os que foram conside- 
rados não índios e outro para a população indígena da região - Centro Comercial Pataxó. Vejamos a descrição deste último:

[...] uma construção circular em alvenaria com paredes pintadas cobertas por telhados tradicionais. O centro vai comportar 74 lojas em 3.800 metros quadrados de área construída. No meio da construção, está sendo instalado um pátio destinado às cerimônias e danças indígenas (http://met.gov. br/500anos/museu.htm).

O fato de se estabelecer um lugar eminentemente comercial para a performance de rituais indígenas indica que houve uma espécie de mercantilização da cultura Pataxó. Ademais, essa mercantilização não se esgotou na apropriação dos rituais como objetos de consumo. A própria demarcação das terras Pataxó foi, em alguma medida, uma estratégia de marketing, pois seu objetivo último era disponibilizar aos visitantes do Museu Aberto um exemplar aproximado de como viviam os índios à época da chegada de Cabral. Ainda sobre o lugar das terras Pataxó nesse contexto, vale lembrar de um outro feito do projeto MADE:

A antiga escola foi demolida para dar lugar ao terminal turístico, fronteiro às terras indígenas, na entrada do parque[Parque Nacional da Coroa Vermelha]. Uma nova escola foi construída no arruamento tradicional de Cabrália (http://www.met. gov.br/500anos/museu.htm).

Ao contrário do que seria legítimo imaginar, ou seja, que as terras indígenas guardariam uma distância razoável dos empreendimentos turísticos da região a fim de resguardar seu meio ambiente e proteger os Pataxó de eventuais contatos indesejados com turistas, o projeto Museu Aberto do Descobrimento optou por construir um terminal turístico vizinho às terras indígenas, manifestando mais uma vez uma perspectiva mercadológica que parece ter guiado os investimentos do governo federal nessa região.

Nas narrativas que dão sentido às atividades do governo federal, os processos de contato entre índios e outros segmentos da população parecem ter tido uma dupla posição: de um lado, demarcaram-se as terras Pataxó e criou-se um simulacro do cotidiano de um povo indígena antes do contato com os portugueses; de outro, estimulou-se um tipo de contato particular, mediado e informado por interesses turísticos, nos quais os índios e suas tradições foram transformados em mercadorias e peças de museu. ${ }^{18}$ Essa perspectiva cria um passado romantizado, em que os processos de contato são ignorados e apagados da história. Tais processos não foram incluídos na representação material exposta no MADE, pois se pretendia realizar uma cópia da terra "virgem" aos contatos com a civilização européia, privilegiando-se imagens cristalizadas do que hoje se imagina ter sido o contexto social e ecológico da época do "descobrimento" processo de reinvenção do paraíso. ${ }^{19} \mathrm{O}$ Museu Aberto do Descobrimento tornou-se, assim, quase que um parque temático, expondo de forma lúdica imagens do que se pensa ter existido no território nacional há 500 anos atrás, promovendo o que Trouillot (1995, p.148) chamou de trivialização de eventos históricos. Isso porque, segundo esse ponto de vista, não foram disponibilizados ao grande público elementos que lhe permitiriam elaborar uma visão crítica das relações de poder que permearam o contexto retratado pelo museu. Optou-se, então, por mostrar ao turista uma visão romantizada do estilo de vida dos índios. Os produtores dessa narrativa não foram nomeados e a relação de poder estabelecida entre eles e os índios, que atuaram ali como personagens coadjuvantes, foi desprezada. Não se levou em conta, inclusive, as conseqüências das relações de contato para a forma como as interações sociais entre índios e não índios se dão atualmente. Os efeitos perlocucionários (Austin, 1999) dos silêncios produzidos pelo Estado foram sentidos no dia 22 de abril de 2000, quando setores da sociedade civil organizada promoveram vários protestos contra a maneira pela qual a chegada e a fixação dos portugueses no Brasil estavam sendo narradas pelo Estado. ${ }^{20}$

Vale lembrar ainda que promover uma imagem exótica dos povos indígenas e, ao mesmo tempo, incentivar o contato entre eles e outros setores da comunidade nacional é uma versão atualizada das exposições universais e coloniais surgidas a partir do século XIX, onde, para celebrar as 
conquistas tecnológicas, políticas e civilizatórias do Ocidente, forjavam-se modelos de aldeias e povoados africanos, asiáticos, americanos etc., sob domínio dos impérios coloniais. Neles se procurava, entre outras coisas, recriar as condições de organização social e ecológica sobre as quais as metrópoles européias diziam encetar seus processos civilizatórios, celebrando-os (Thomaz e Lichtenthäler, 1996; Montero e Thomaz, 1996).

\section{Motes da narrativa estatal: comemorar o descobrimento}

Discuti até o momento algumas das estratégias oficiais e oficiosas que, em conjunto, trabalharam para que o dia 22 de abril e a chegada dos portugueses à Bahia se tornassem um evento a ser lembrado e celebrado. ${ }^{21}$ Explorarei a seguir os fragmentos das atividades oficiais para, a partir delas, mapear como o Estado desejava que esse evento fosse percebido pela população.

É importante esclarecer que as atividades estatais não se restringiram aos eventos ocorridos em 22 de abril de 2000, mas encontram-se diluídas numa extensa agenda, inaugurada no início do segundo mandato de Fernando Henrique Cardoso. ${ }^{22}$ É no interior dessa agenda, portanto, que as festividades do dia 22 ganham sentido.

As fontes de pesquisa privilegiadas aqui são as home pages oficiais. Nelas estão registradas as agendas estatais de "comemoração", bem como os discursos e as imagens que denotam claramente a ideologia afirmada nesses eventos. ${ }^{23}$ Nesse sentido, é importante resgatar a função que o Estado atribuiu às "comemorações" e à disponibilização de sua agenda na rede mundial de computadores:

[...] O objetivo de reunir as comemorações, projetos e histórias que constroem essa página comemorativa dos 500 anos do Brasil não é outra senão ajudar a memória da Nação. Fornecer novas cores para o futuro do País, ainda que incompletas, pois a própria bistória assim o é, repleta de versões que se sobrepõem e até se excluem. [...] Partindo da costa em que se começou a contar 500 anos de história, narra-se, agora, a descoberta de um modelo para que índios, brancos e negros e todas as raças que se incorporaram a esse abraço de 8 milhões de $\mathrm{Km}^{2}$ - contem os próximos séculos a bordo de qualidade de vida, justiça social e preservação cultural e natural. [...] O Brasil que não quer esquecer seu passado, redescobre o futuro (http://www.met.gov.br/500anos).

O Estado assume, literalmente, que uma das funções das "comemorações dos 500 anos" é oferecer à nação elementos para a construção de uma memória coletiva. Assim, considerando-se que toda narrativa histórica, ao afirmar determinados acontecimentos, necessariamente oculta outros (Trouillot, 1995; Das, 1995), cabe-nos perguntar, diante do problema aqui analisado, quais foram as narrativas privilegiadas pelo Estado, para, a partir daí, diagnosticarmos, pelo não-dito, todas as outras que foram silenciadas. Discutirei o perfil das atividades que constaram da agenda oficial com o intuito de verificar em que medida as questões ali propostas se repetem, revelando, quiçá, um padrão ideológico.

As atividades, desenvolvidas no Brasil e no exterior, receberam apoio ou financiamento do Estado e uma marca que as qualificou como evento "comemorativo oficial dos 500 anos" do país. Antes de examinar o perfil dessas atividades, uma análise do símbolo de identidade visual atribuído a elas revelará um dos eixos ideológicos aí afirmados.

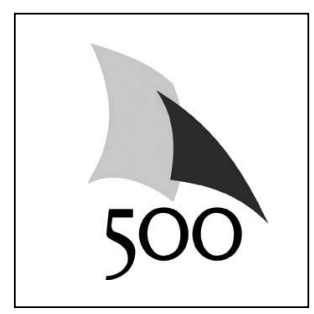

A marca oficial do $\mathrm{V}$ Centenário define-se pela sobreposição de duas velas, em verde e amarelo - cores-símbolo da identidade nacional brasileira - dispostas acima do número 500, pintado em cor azul, sobre um fundo branco. Num primeiro olhar, já se percebe que suas cores são as mesmas da bandeira brasileira, revelando, assim, certa identidade gráfica com ela e, quiçá, certo compartilhamento de funções, na medida em que 
ambas evocam a existência de uma singularidade nacional. No entanto, se é possível reconhecermos essa similaridade, não podemos deixar de atentar para o papel semiótico das velas. Se a bandeira nacional pode ser abordada como símbolo da existência de um país soberano - que deixou sua condição de colônia -, a presença das velas evoca um vínculo primeiro com o além-mar, que encontra em Portugal e em suas caravelas seu sentido mais profundo. Aponta-se para o fato de que os "500 anos do Brasil" se tornou possível porque há 500 anos existiram embarcações - daí a presença das velas, índices, nesse contexto, das caravelas - que permitiram a chegada de outros povos ao território que posteriormente veio constituir o Estado-nação brasileiro. Não obstante saibamos que tentativas de colonizar essas terras tenham sido feitas por outros países europeus, nas "comemorações dos 500 anos" o vínculo de identidade nacional foi construído com Portugal. Portanto, se é possível, num primeiro momento, dizer que a presença das velas evoca uma tentativa de o Brasil se colocar como tributário de variadas tradições européias, uma análise da agenda oficial nos mostra que tais tradições dizem respeito exclusivamente a Portugal.

A agenda oficial de comemorações, entre os meses de abril e dezembro de 2000, revela, para além da diversidade do perfil dos eventos, uma recorrência de temas: 1) vínculo cultural, social, econômico e político do Brasil com Portugal; ${ }^{24}$ 2) esporte, sobretudo, futebol; 3) desenvolvimento do país, especialmente em relação a temas que têm recebido uma maior atenção internacional, como meio ambiente e educação; ${ }^{25}$ 4) igreja católica; e 5) diversidade artística nacional. ${ }^{26}$

Além disso, foram classificados como atividades oficiais uma série de projetos desenvolvidos pelo MET (Ministério do Esporte e Turismo): 1) Chama do Conhecimento: entrega ritual de três tochas, interpretadas nesse contexto como "chamas do conhecimento," ao presidente da república por representantes de comunidades indígenas, populações afro-descendentes e portugueses; 2) Farol do Saber: criação de bibliotecas públicas em regiões do país consideradas carentes; 3) Cruz Sagrada: substituição da cruz de madeira de Santa
Cruz da Cabrália - local onde se afirma ter sido celebrada a primeira missa no Brasil - por uma de metal, criada especialmente para as comemorações; 4) Projeto Monumenta: recuperação de centros arquitetônicos coloniais brasileiros; 5) Nau Capitânia: construção de uma réplica da caravela portuguesa que chegou ao Brasil comandada por Cabral; 6) Projeto Documenta: resgate e registro de documentos sobre o Brasil produzidos na Europa; 7) Expo 2000 Pavilhão Brasil: concepção e construção do pavilhão brasileiro na Feira de Hannover; 8) Projeto Pau-Brasil: plantio de sementes de pau-brasil, que é aí considerada a árvore símbolo da identidade nacional; 9) Projeto Marcos Históricos: construção de um marco das comemorações oficiais dos 500 anos em cada uma das unidades da Federação; e 10) Museu Aberto: projeto comentado anteriormente.

É, pois, a partir desses projetos e eventos que os discursos do presidente da república ganham seu sentido. Ao analisá-los poderemos notar uma redundância temática em relação às questões evocadas, o que revela a presença de um certo padrão ideológico nas "comemorações" promovidas pelo Estado.

No dia $1^{\circ}$ de janeiro de 2000 , o presidente Fernando Henrique Cardoso recebeu, vinda de Portugal, a última das três tochas - "chamas do conhecimento". Naquele momento, ele proferiu as seguintes palavras:

Recebo nesse instante, vinda de Portugal, a terceira "chama do conhecimento". A primeira, recebi em São Raimundo Nonato, no Piauí, das mãos de chefes indígenas. Logo depois, Ruth Cardoso recebeu, nos sertões de Goiás, das mãos dos Calungas, descendentes de escravos africanos, a outra das chamas simbólicas do encontro entre raças e culturas que formou o Brasil. No romper do ano 2000, quando nosso país completará seus 500 anos, rendemos homenagens aos formadores de nossa civilização: brancos europeus, de fala portuguesa e fé em Cristo, índios autóctones com dezenas de falas e crenças e negros africanos, também diversificados na língua e na cultura. [...] Somos talvez a maior nação multiracial do mundo Ocidental, senão em número de habitantes, na capacidade integradora da civilização que fundamos. [...] E essa identidade dá-nos a base para a entrada no novo milênio, o da "civilização glo- 
bal"; nos distingue pelos valores da tolerância, permite que reflitamos, a partir dela, o quanto conseguimos caminhar nesses 500 anos. [...] Pátria da imigração, de braços abertos aos que aportam, como Cristo que nos guarda do alto do Corcovado. [...] Terra da solidariedade. É isso que pedimos como benção nesta entrada do Milênio. [...] Paz e amor são nossos lemas [...]. Meus amigos, quando os portugueses aventuraram-se pelos oceanos na ânsia de descobrir novas terras e novas gentes deram a marca da modernidade: a descoberta do outro, o reconhecimento da variedade e da diferença [...].

A afirmação da diversidade cultural do país é o tema principal dessa passagem. A "civilização" brasileira foi formada a partir de três povos: brancos europeus; índios autóctones e negros africanos que, em comunhão, deram origem ao que o presidente considera a "maior nação multiracial e multicultural do mundo Ocidental". Os brancos europeus têm aí uma identidade bastante definida: são brancos nascidos em Portugal. É a partir desse vínculo que se explora a formação do Brasil. As origens dos negros e índios, contudo, não são citadas, apesar de se afirmar que havia uma diversidade entre eles. Segundo essa narrativa, o Brasil é apresentado como o lugar da tolerância, da solidariedade, da paz, do amor e do respeito aos diferentes, "marcas da modernidade" inauguradas por Portugal. Qualquer índice de conflito entre os povos considerados formadores da nação é obliterado; afinal, como afirma o presidente, esta é a terra da solidariedade, uma forma de sociabilidade que não combina com embates. Essas mesmas idéias são repetidas, com algumas nuanças, no discurso do dia 22 de abril de 2000:

[...] Brasil e Portugal escrevem hoje um novo capítulo dessa trajetória comum. Reafirmam juntos, na entrada do novo século, a sua vocação de entendimento e cooperação, que não é só antiga. Diria que é permanente, definitiva. Nós nos reunimos aqui para celebrar uma herança e reafirmar um sonho. Celebrar a herança do país cujas raízes nossos antepassados fincaram nesta terra e regaram com seu suor e sangue. Reafirmar o sonho da sociedade livre, justa e solidária que hoje nossa geração tem a vontade e a oportunidade de erguer sobre os alicerces destes 500 anos. [...] A história nos ensina a admirar a bravura dos nave- gantes que primeiro fincaram a bandeira de Portugal deste lado do oceano. Admirar a fibra dos desbravadores que estenderam o domínio português pela costa e ao interior do continente. A bravura dos combatentes que garantiram a posse do território no período colonial; a habilidade dos estadistas que souberam manter a integridade do Brasil na Independência e conseguiram a demarcação pacífica das nossas fronteiras durante o Império e no início da República [...].

Mais uma vez afirma-se que a fundação do país se deu com o "descobrimento" dos portugueses. Aliás, não só a fundação da nação, mas a definição de seu território. A expansão, a demarcação e a manutenção de fronteiras e da soberania sobre elas são abordadas como um processo pacífico, silenciando-se, nesse momento, o extermínio e a escravização de populações indígenas e negras que foram concomitantes a essa expansão. Além disso, sabe-se que a demarcação de fronteiras à época do Império e da República implicou a morte de muitos homens em revoltas como Farropilha, Cabanagem, Sabinada, Contestado, entre outras. Esses acontecimentos foram sistematicamente esquecidos (Das, 1995, p. 129) para dar lugar à idéia de que a integridade do país foi mantida de maneira tranqüila. A palavra solidariedade aparece novamente, não mais como realidade, mas como quimera.

A afirmação de que o Brasil é formado a partir da mistura de três raças é a tônica do projeto Chama do Conhecimento. A percepção de que essa mistura deu origem a uma nação multicultural parece ser a mensagem transmitida através da temática diversidade artística nacional. A diversidade artística é tomada como um ícone para a idéia de uma nação multicultural.

Ao comparar a agenda e os projetos oficiais com os discursos de Fernando Henrique vemos que o vínculo do Brasil com Portugal é um dos temas dominantes das "comemorações oficiais". Nas duas narrativas do presidente, a ligação do Brasil com Portugal é o primeiro elemento evocado a fim de dar sentido às "comemorações dos 500 anos". Aliás, é a chegada dos portugueses ao continente americano que inicia a cronologia histórica que tornou possível a concepção de que o 
Brasil estaria completando 500 anos em 2000, mesmo que a idéia de um Estado-nação independente e soberano só tenha se tornado realidade no século XIX. No âmbito das atividades desenvolvidos pelo MET, observa-se essa relação nos seguintes projetos: Nau Capitânia - a viagem de Cabral é a pedra angular do sentido de se construir uma réplica das embarcações portuguesas da época do descobrimento; Chama do Conhecimento - é cultivada a idéia de que o povo português é um daqueles sobre os quais se formou a "civilização brasileira"; Projeto Monumenta - a restauração de centros arquitetônicos remanescentes da época colonial preserva na memória nacional a presença portuguesa no país; e Projeto Documenta - os documentos a serem recuperados fazem parte, sobretudo, da coleção do Arquivo Ultramarino de Lisboa.

Como corolário do legado português ao Brasil, a presença da Igreja Católica é lembrada em várias ocasiões na agenda de comemorações, uma vez que missas e a própria assembléia anual da CNBB receberam a marca de evento oficial. $O$ projeto Cruz Sagrada é outro índice da presença dessa instituição e de seus valores na história do país, pois apresenta, como monumento de "comemoração dos 500 anos", uma cruz fixada no local onde se diz ter sido celebrada a primeira missa no Brasil. Assim, se lembramos que o objetivo das comemorações dos 500 anos era oferecer elementos para a construção de uma memória nacional, verificamos que não somente eventos de natureza secular devem ser lembrados, mas outros de caráter religioso. Afirma-se, por meio deles, que a Igreja Católica tem lugar próprio na memória nacional. Não é por acaso que Fernando Henrique, então representante da nação, ao tecer comentários em relação ao passado e ao futuro do Brasil, tenha se utilizado de metáforas retiradas do universo cristão e católico, o que demonstra mais uma vez que a auto-imagem do país é perpassada pela cosmologia apresentada por essa instituição. ${ }^{27} \mathrm{Ao}$ apresentar o Brasil como a terra da cordialidade e da solidariedade, o presidente afirma:

Pátria da imigração, de braços abertos aos que aportam, como Cristo que nos guarda do alto do
Corcovado. [...]

Soubemos manter a paz secular com os nossos vizinhos; estamos lutando para que ela exista entre nossos irmãos brasileiros, no catecismo da solidariedade [...].

Não queremos perder a cultura da solidariedade, não aceitamos discriminações de raça, de religião, ou de gênero. Queremos o amor ao próximo com dimensão prática: que a impunidade não encubra a injustiça (discurso de $1^{\circ}$ de janeiro de 2000, grifos meus)

Como se observa, estão ausentes dos eventos e dos discursos oficiais quaisquer referências diretas aos conflitos que permearam a construção do país como unidade nacional. Há, inclusive, uma intenção deliberada nesse esquecimento. O projeto Cruz Sagrada é justificado com base nos seguintes argumentos:

A cruz erguida nos anos 70, em Coroa Vermelha, está sendo substituída por uma nova, de metal prateado, mais luminosa e bonita. A idéia é eliminar a idéia de martírio e sofrimento, apontando para uma perspectiva de paz e esperança.

Essas conexões semânticas, em associação com discursos que celebravam o caráter multicultural do país e a ausência de conflitos étnico-raciais em seu interior, podem facilmente resvalar para uma retomada da idéia de democracia racial como sinal diacrítico da formação da sociedade brasileira. Ademais, é evidente, no discurso presidencial, a celebração de um certo lusotropicalismo, que atribui a Portugal a fundação de um dito tempo moderno, cuja característica principal estaria no respeito pela diferença. Nesse sentido, os discursos de Fernando Henrique Cardoso aproximam-se bastante dos elaborados por Gilberto Freire (1940) a respeito da civilização que os portugueses teriam criado. ${ }^{28}$

Ainda a esse respeito, nota-se que a herança deixada ao país, digna de preservação e discussão no âmbito das "comemorações dos 500 anos", é o meio ambiente, a natureza e o desenvolvimento auto-sustentável, e não qualquer tipo de revolta ou revolução que questione os padrões de sociabilidade considerados inadequados: 
Estamos nos preparando para participar da nova Era, herdeiros de uma natureza exuberante e variada, queremos respeitar o meio ambiente, para legá-lo como fonte de vida às gerações futuras (discurso presidencial de $1^{\circ}$. de janeiro de 2000).

Marilena Chauí (1994) aponta a existência de conexões semânticas similares quando analisa alguns dos mitos fundadores do que ela denomina matriz teológico-política do populismo dominante e do messianismo dos dominados no Brasil. Um deles é o mito da "visão do paraíso", valendo-se da expressão de Sérgio Buarque de Holanda (1982). Assim, discutindo a simbologia da bandeira brasileira, em oposição a outras elaboradas no mesmo período - geralmente de três cores-símbolo que evocariam acontecimentos sociopolíticos dos quais a bandeira é a expressão - seguindo o padrão da bandeira francesa -, Chaú evidencia o fato de a bandeira brasileira possuir quatro cores que simbolizam elementos da natureza, apropriados como símbolos da identidade nacional. O verde representa as imensas e inigualáveis florestas, o amarelo, a riqueza do solo, e o azul, a beleza do céu limpo e estrelado. O hino nacional brasileiro, segundo Chauí, também apresenta essas mesmas associações, na medida em que "canta mares, céus, sóis, bosques, nossa vida de mais amores"' (Chauí, 1994, pp. 23-24).

O meio ambiente e o desenvolvimento sustentável foram os temas inspiradores do pavilhão brasileiro na Feira de Hannover e de outros eventos que constaram na agenda estatal de comemorações. O projeto Pau Brasil, por exemplo, investiu no plantio em larga escala da árvore que emprestou seu nome ao país. Não houve, portanto, nenhuma atividade na agenda oficial que tratasse dos conflitos que envolveram a construção do país, como a escravidão, as lutas pela Independência no século XVIII e as revoltas que marcaram o período colonial, o Império e a República. Investiu-se na preservação de sítios arquitetônicos desses períodos, como previsto no projeto Monumenta, mas retira-se do âmbito das coisas a serem lembradas as relações de poder entre aqueles que habitaram esses cenários. Até o momento em que foi possível ignorar os protestos da sociedade civil, não se fez referência às relações de poder e aos conflitos entre negros, índios e brancos, que permearam a história da nação. ${ }^{29}$ Aliás, poder-se-ia mesmo afirmar que os processos de interação social e os conflitos deles decorrentes foram apagados dos relatos contados pelo Estado. Fez-se referência aos mitos fundadores da nação brasileira como o encontro das três raças e o nascimento do espírito de cordialidade, ambos ocorridos em um cenário de exuberância ecológica - e, abruptamente, os discursos deslocaram-se para acontecimentos contemporâneos, como os investimentos do governo de então, obliterando-se os diversos eventos históricos que protagonizaram a construção nacional. Fatos como a proclamação da Independência e da República, gestados, em certa medida, em função de conflitos com Portugal, não são citados, pois o valor dominante dessas celebrações parece ter sido o cultivo dos vínculos amistosos com o país ibérico e não as disputas estabelecidas nos primórdios do Estado brasileiro. Nesse contexto, Portugal foi construído como uma espécie de ascendente do Brasil e, tal como um ente que participa de uma mesma família, com a qual se compartilha inclusive uma mesma língua, segue-se a ética da casa (DaMatta, 1991) ao com ele se relacionar. Participam dessa ética relações de complementaridade e não de oposição.

A afirmação recorrente de que o Brasil é a terra da solidariedade e cordialidade nega a presença de embates e disputas em nossa história e endossa a narrativa estatal que pretende abordar a trajetória do país como algo para além de um "jogo entre mocinhos e bandidos". Evidentemente, o potencial analítico disruptivo dessa perspectiva é bastante grande, mas, dada a forma como foi utilizada pelo Estado, acabou se tornando tão essencialista e romântica quanto aquela denominada maniqueísta, uma vez que, ao ignorar as diferentes posições de sujeito e, portanto, de poder entre os vários segmentos sociais que participaram da construção nacional, simplificou a história do país, estagnando-a em dois momentos: no tempo de criação dos mitos fundadores da identidade nacional e no tempo das políticas engendradas pelo governo Fernando Henrique Cardoso.

Trouillot (1995), com o objetivo de precisar como operam as relações de poder na produção 
de narrativas históricas, elaborou algumas advertências metodológicas importantes para a discussão aqui realizada. Para ele, a produção de silêncios é um dos principais instrumentos do qual faz uso o poder na construção dos relatos históricos. $O$ autor adverte que os silenciamentos inscritos nesses relatos podem ser produzidos em quatro momentos diferentes: 1) na definição das fontes; 2) na agregação das fontes; 3) na recuperação dos fatos; e 4) na criação propriamente dita da narrativa histórica, quando se elaboram as retrospectivas significantes.

Observam-se nas narrativas oficiais sobre os "500 anos do Brasil" pelo menos dois dos tipos de silenciamento identificados por Trouillot: o que se faz presente no resgate dos fatos e o que opera na forma pela qual se agregam esses fatos. Na retórica estatal em torno dos "500 anos de história do país" recuperam-se somente eventos muito particulares, quais sejam, "o encontro das três raças" e a fundação de um padrão de sociabilidade pautado por relações amistosas. A agregação dos fatos resgatados é narrada a partir de um valor específico: a cordialidade. Ela é o valor que dá o tom da retrospectiva significante tecida pelo Estado neste momento.

Outra conexão semântica a destacar é a utilização da expressão "descobrimento do Brasil", que denuncia a maneira pela qual a chegada dos portugueses em terras do continente americano é interpretada. Eles são considerados protagonistas de um encontro entre povos que estabelece a inserção dessas terras e das populações que as habitavam na história ocidental. Como afirma Oliveira (2000, p. 197), "a visão de paraíso e a noção de descobrimento e não fundação, produzem uma naturalização da história”.

Outro padrão narrativo passível de identificação nos discursos oficiais é a forma como são arranjados os conteúdos que evocam os mitos fundadores da nação em conjunção com medidas de incorporação cívica que, nesse contexto, são associadas a idéias de modernidade, progresso e justiça. Nos discursos de Fernando Henrique Cardoso, após a citação dos mitos fundadores da nação, são apresentas medidas de inclusão social protagonizadas pelo Estado ao longo do tempo e, por vezes, especificamente pelo seu governo. ${ }^{30} \mathrm{~A}$ afirmação dessas medidas fez-se também por meio de eventos e projetos desenvolvidos pelo MET, dos quais se destacam os seminários sobre o desenvolvimento, cujos temas são predominantemente a democratização da educação e a preservação do meio ambiente, e o projeto Farol do Saber, cujo objetivo é construir bibliotecas públicas em regiões carentes. ${ }^{31}$

Pode-se reconhecer nas atividades desenvolvidas pelo Estado para a "comemoração dos 500 anos do descobrimento" a recorrência de fenômenos apontados por Elias (1972, 1997) Bendix (1977) e Reis (1998) como típicos dos processos de nation-building. Participam desses processos tanto retóricas que elaboram e engendram um passado nacional comum, como discursos que afirmam a integração de segmentos sociais mais baixos da população numa comunidade moral organizada em torno de direitos políticos, sociais e individuais específicos. Daí conclui-se que fenômenos a princípio analisados de forma segmentada - como, por exemplo, a emergência de partidos políticos de massa, as idéias a respeito de nação, industrialização e luta de classe - participam todos do processo de desenvolvimento histórico do Estado-nação que, por sua vez, se fortalece na medida em que amplia a possibilidade de participação na comunidade moral criada por ele.

\section{Dos efeitos perlocucionários das come- morações oficiais: sobre a gestação social dos conflitos}

Paralelamente às atividades oficiais de comemoração, ocorreram eventos alternativos agregados sob o nome de Movimento Brasil: 500 anos de resistência indígena, negra e popular, dos quais faziam parte segmentos de oposição política ao governo - como o Movimento dos Sem Terra (MST), o Movimento Negro Unificado -, sindicatos, organizações da igreja católica, partidos políticos de oposição e estudantes, além de diversas organizações representantes dos interesses indígenas. A principal atividade promovida por essa coalizão foi uma marcha nacional que saiu de vá- 
rios pontos do país, intitulada Brasil Outros 500. O tom predominante das manifestações era o de questionar os relatos que vinham sendo pronunciados pelo Estado em torno da "comemoração do descobrimento". ${ }^{32}$ Os representantes desse movimento afirmavam que as relações desiguais de poder que se instauraram no país entre índios, negros e portugueses não poderiam ser silenciadas $^{33}$ e que o movimento era uma tentativa de apresentar uma outra versão do que havia sido os "500 anos" do país.

Aproxima-se a data - 22 de abril de 2000 - que nos fará refletir sobre 500 anos atrás, quando um grupo armado de portugueses desembarcou nestas áreas, com a meta de anexá-la como território colonial. Aqui viviam, há mais de 40 mil anos, mais de 5 milhões de pessoas, pertencentes a cerca de 970 diferentes povos. Eram os legítimos donos destas terras, possuidores de tudo - menos de anticorpos para doenças européias, de armas mortais à base de pólvora e chumbo, nem o impulso de violência, depredação e saque. Disto, eram portadores privilegiados aquele grupo de homens maltrapidos e doentes que desceu na praia da hoje Cabrália, sul da Bahia, cinco séculos atrás, dizendo que estavam descobrindo o Novo Mundo e que para estas terras traziam seus ideais de civilização, progresso, e evangelização. [...] Fazemos uma leitura da nossa história a partir de um lugar definido - dos que sofreram e lutaram contra a espoliação colonial e a exploração de classe [...] pretendemos revelar a verdade histórica vivida pelos povos indígenas, pelos povos negros escravizados, pelas classes sociais e setores populares explorados e excluídos [...]. Para as comemorações oficiais inexiste a noção de conflito, hoje como no passado. Para nós, pelo contrário, a noção de conflito é central na história como no presente, projetando-se no futuro [...] ( Manifesto Brasil: 500 anos de resistência indígena, negra e popular, apud Herschamann e Pereira 2000, p. 208).

Esse discurso afirma-se por "denunciar" os fatos que foram sistematicamente silenciados pela narrativa oficial, como os conflitos e a violência que fizeram parte da história do país. Tal silenciamento gerou efeitos não esperados no momento de sua produção. As narrativas alternativas, elaboradas por oposição às oficiais, são, portanto, produtos perlocucionários das últimas (Austin 1999). Nesse contexto, a própria utilização da palavra "comemoração" foi politizada, revelando as disputas acerca das ideologias da linguagem presentes nesses eventos (Kroskrity, 2000). Marina Silva, senadora pelo Partido dos Trabalhadores do Acre e integrante da marcha Brasil Outros 500, afirmou:

[...] festejo é desrespeito para com aqueles que foram expropriados e massacrados. Eu até digo que nem comemorar, nem festejar. Talvez o sentido correto seja o de celebrar, porque quando você celebra, você evidencia o que é negativo para reparar, e aprofunda o que é positivo para ampliar. Então, o sentido desses 500 anos para mim é celebrar (Depoimento retirado do vídeo Terra à Vista, produzido pela Universidade Católica de Brasília, no âmbito do Projeto Terra à Vista, do curso de comunicação social).

A expectativa do Movimento Brasil era reunir cerca de quarenta mil pessoas na região de Porto Seguro. Temendo que as comemorações oficiais fossem prejudicadas por conta dessas manifestações, o governo federal e o governo do estado da Bahia montaram um forte esquema de segurança na "Costa do Descobrimento", afirmando publicamente que membros do MST seriam proibidos de entrar na região e de fazer qualquer tipo de protesto. O clima de tensão gerado por essas declarações fez com que a discussão acerca dos festejos tivesse mais destaque na imprensa nos dias 22 e 23 de abril do que os próprios eventos oficiais, ${ }^{34}$ de forma que a agenda estatal e as performances do presidente foram alteradas. ${ }^{35}$ Pela primeira vez, nos discursos oficiais, as relações de poder que permearam a construção da nação foram citadas e os protocolos relativamente quebrados. No discurso de 22 de abril de 2000, Cardoso, depois de saudar o presidente de Portugal e apresentar algumas das conquistas de seu governo, afirmou:

Celebrar uma herança histórica não significa idealizar o passado. Hoje no Brasil nós temos uma consciência aguda das chagas sociais que fazem parte da herança destes quinhentos anos.

A expansão das fronteiras daquilo que viria a ser o território brasileiro deu-se ao preço da eliminação de povos indígenas, como hoje nos lembram - e é preciso lembrar - seus representantes aqui em Porto Seguro. Alguns, equivocadamente, acham 
excessiva a extensão das terras indígenas demarcadas nos últimos anos - algo como 11\% do território nacional. Na verdade isso representa uma reparação tardia dessa dolorosa marca do nascimento da nação brasileira. [...] Outras vozes de protesto e reivindicação se fazem ouvir nesta celebração. Elas são ecos do passado escravista, oligárquico e patriarcal que até hoje pesa sobre a sociedade brasileira e faz dela uma das sociedades mais injustas do mundo. [...] Mas a mensagem mais importante que as vozes dos excluídos nos trazem não diz respeito ao passado, e sim ao futuro. Elas anunciam que chegou o momento de virar a página da exclusão na história do Brasil. O momento chegou porque com o nível de desenvolvimento que nós chegamos, a pobreza do país não serve mais de desculpa para a miséria do povo. [...] O Brasil que rompe as amarras do atraso econômico e, com a bússola da democracia, toma o rumo da inclusão social, é um país que tem tudo para encarar o mundo com autoconfiança. Somos uma nação sem conflitos externos e livre dos conflitos étnicos e religiosos internos que flagelam outras partes do planeta. Somos um povo com uma unidade lingüística e cultural notável, considerando as dimensões do território e da população. Temos, sim, razão de nos orgulhar disso tudo.

O presidente toma certos fatos históricos passado escravista, oligárquico e patriarcal - como "chagas". Isso porque teriam contribuído para tornar a sociedade brasileira uma das mais injustas do mundo. O sentido predominante que ele atribui às vozes de protesto é o de que elas desejam superar as injustiças atuais. Tomando para si esse mesmo desejo, Cardoso sugere que o país tem vantagens comparativas importantes para a superação das desigualdades sociais - altos índices de desenvolvimento político, social e econômico e, sobretudo, um "espírito" inventivo e respeitador das diferenças. A síntese de fenômenos que $a$ priori parecem possuir naturezas bastante distintas, tais como industrialização, desenvolvimento, mitos fundadores da nação, entre outros, mais uma vez se manifesta nesses eventos. Além disso, nota-se que a forma como o discurso do presidente está organizado passa a idéia de que, não obstante existam ainda sérios problemas no país para se alcançar níveis de inclusão social mais altos, eles serão superados em função de um ethos peculiar ao povo brasileiro, marcado por, entre outras coisas, o respeito às diferenças, a unidade lingüística e cultural existente, a ausência de conflitos étnicos e religiosos e a capacidade de negociação e tolerância. Para Cardoso, mais importante do que reconhecer os conflitos é a crença de que existe algo maior unindo indivíduos de posições diferentes. Utilizando essa narrativa, o presidente faz uso de uma estratégia comum aos discursos de construção nacional - tal como foram abordados por Elias (1997) e Bendix (1977) - tomando-os como instrumento que ofusca as diferenças e os embates entre grupos sociais diversos. Ao organizar seu discurso dessa maneira, o presidente não nega a existência de conflitos, mas os subordina a uma lógica conciliatória. ${ }^{36}$

Segundo autores como Tambiah (1985), Turner (1957, 1972) e Gluckman (1963), entre outros, os rituais, na maior parte das vezes, têm a função de repor a ordem institucional e moral das sociedades, mesmo quando tematizam situações de conflito, e só podem ser apreendidos como parte de um processo social que está para além deles. No caso aqui estudado, a inserção da temática do conflito nos discursos oficiais ocorreu em conseqüência dos protestos da sociedade civil, os quais foram elaborados em função dos silêncios produzidos pelo próprio Estado. O Estado, por sua vez, acaba por reconhecer alguns dos embates que perpassaram a construção da nação, mas o faz para no mesmo momento em que os subordina a um valor superior, a cordialidade. Como em um drama social (Turner, 1957), os conflitos anunciados pelo Estado são utilizados para reafirmar a coesão e a solidariedade da comunidade nacional: "Queremos preservar essa cordialidade [...] para amenizar a frieza do chamado 'mundo moderno'”, afirmou o presidente em $1^{\circ}$ de janeiro do ano 2000.

\section{Considerações finais}

Se, como afirma Tambiah (1985), os rituais são sistemas simbólicos de comunicação e, como declara a home page do MET, a função das "comemorações dos 500 anos de descobrimento" era oferecer elementos à memória da nação, gostaria de sintetizar os principais valores e idéias afirma- 
dos por meio dos eventos discutidos e que devem, portanto, constar na memória da nação, conforme ela foi imaginada pelo Estado no governo Fernando Henrique Cardoso.

Primeiramente, foi papel do Estado, juntamente com outras instituições, intensificar a idéia de que o dia 22 de abril era uma data digna de celebração. Para tanto, ele e atores diversos da sociedade civil trabalharam em conjunto, apresentando a data como aquela em que o Brasil faria "500 anos". Revitalizaram-se alguns dos mitos de fundação nacional e se transformou a região de Porto Seguro em um Museu Aberto, no qual índios, brancos e afro-brasileiros - e suas respectivas comunidades - se tornaram peças em exposição, sustentando uma relação ambígua diante das idéias de contato e miscigenação tal como pensadas pelo Estado. Nesse contexto, foram vendidos simulacros de comunidades alheias ao contato, processo esse que implica uma interação entre quem compra e vende, aproximando grupos cujo suposto valor de venda estaria na distância e no exotismo dela conseqüente.

O ethos da cordialidade foi o valor dominante das comemorações oficiais. A esse valor subordinou-se a forma como as relações entre portugueses, populações indígenas e afro-descendentes foram narradas: relações de amizade e irmandade, nas quais não havia conflitos, mas apenas troca de traços culturais. A chegada dos portugueses ao novo mundo é abordada como fundadora da nação, inaugurando a cronologia que tornou possível se comemorar os "500 anos" no ano de 2000.

A formação da nação multiracial e multicultural, tal como o presidente denominou o Brasil, baseou-se na mestiçagem entre portugueses, negros vindos da África e as populações aborígenes que habitavam as terras americanas. Os discursos produzidos por ocasião dos festejos retomam a fábula das três raças e um certo ideal lusotropical, disponibilizado por uma metalinguagem (Tambiah, 1985, p. 139) que abre espaço para a retomada do mito da democracia racial, embora ele não seja explicitamente citado.

A presença da Igreja Católica em nossa história é outro traço da ideologia afirmada pelo Estado. Trata-se da única instituição religiosa que participou das "comemorações dos 500 anos". Sua cosmologia serviu de base, inclusive, para algumas das metáforas utilizadas pelo presidente para definir as características do Brasil.

Durante a maior parte dos eventos, esqueceuse sistematicamente (Das, 1995, p. 129) de narrar as relações de poder instauradas entre portugueses, negros, índios e outros segmentos étnicos que formaram o que hoje se denomina nação brasileira. Por mais curioso que possa parecer, ao se propor a contar a história do país como resultado de processos de interação entre segmentos populacionais diversos, o Estado acaba por negá-la, na medida em que só resgata os mitos fundadores da nação, deslocando, posteriormente, seu discurso para políticas contemporâneas de inclusão social. O que se apresenta como a herança, digna de preservação, são as paisagens naturais. ${ }^{37}$

Cedendo aos protestos da sociedade civil, o Estado finalmente reconheceu que índios e negros, bem como outros segmentos sociais subalternos, foram os mais prejudicados durante o $n a-$ tion-building brasileiro. No entanto, ao reconhecer as "chagas" do passado, o Estado delas se apropria para reafirmar os valores que, de sua perspectiva, dão unidade ao país: cordialidade, diversidade e solidariedade.

Seria ingênuo imaginarmos que alguma retórica de integração nacional pudesse ser construída de outra forma que não através de um discurso de inclusão e a partir de uma certa homogeneização da população. Elias (1972), Bendix (1977) e Anderson (1989) mostram que esse tipo de discurso foi recorrente nos processos de formação da maioria dos Estados-nações europeus. Nesse sentido, não se trata aqui de exigir que o Estado elabore um discurso sobre a nação que privilegie sistematicamente situações de conflito, na medida em que, assim, ele estaria minando a possibilidade de existência da comunidade moral que ele próprio pretende fortalecer. Isso não significa, porém, que não se possa construir imagens mais verossímeis, que representem o perfil heterogêneo da população, bem como os processos históricos que lhe atribuíram existência.

A estratégia narrativa adotada pelo Estado para contar como se deu o processo de nation- 
building no Brasil acarretou-lhe um alto custo simbólico. Pode-se dizer que as "comemorações oficiais dos 500 anos" do Brasil foram entendidas por alguns setores da sociedade como mais um índice da opressão estatal sobre grupos considerados subalternos na comunidade nacional. A imagem de um índio ajoelhado diante de um batalhão de policiais da PM da Bahia, estampada nas primeiras páginas de grandes jornais brasileiros de 23/04/2000, foi interpretada como uma versão atualizada do processo de dominação branca e portuguesa sobre as populações indígenas e afro-brasileiras.

O Brasil, ao celebrar uma "data de nascimento" exclusiva, distinta dos demais países da América, que tomaram a data de 12 de outubro de 1992 como motivo de comemorações e protestos, declara, indiretamente, que se vê como portador de uma identidade nacional bastante distinta da de seus vizinhos norte e latino-americanos. Contudo, tal como nas "comemorações do V Centenário do Descobrimento da América”, o V Centenário do Brasil foi construído como uma data em que se sobrepuseram três tempos histórico-morais:"O século XVI, com o descobrimento e a conquista; o século XIX, com a construção das memórias nacionais e o século XX, com a crise dos Estados nacionais e a explosão das etnicidades" (Montero, 1996, p. 22).

\section{NOTAS}

1 Uso aqui a noção de ideologia tal como proposta por Geertz (1989, p. 203): "Enquanto a ciência é a dimensão do diagnóstico, de crítica da cultura, a ideologia é a dimensão justificadora, apologética - refere-se à parcela da cultura que se preocupa ativamente com o estabelecimento e a defesa dos padrões de crença e valor".

2 Para Tambiah (1985), os rituais são sistemas simbólicos de comunicação constituídos por seqüências ordenadas de palavras e atos que, fazendo uso de múltiplos meios, guardam graus definidos de formalidade, estereótipo, condensação e redundância. A análise semiótica dos rituais inspira-se em três preceitos principais: 1) deve-se analisar os rituais como eventos felizes ou infelizes, no sentido de cumprirem ou não as funções às quais se propõem; 2) deve-se atentar para as várias funções de cada ato ritual segundo os critérios de classificação dos atos lingüísticos apresentados por Jakobson (1965); e, por fim, 3) deve-se observar os vários tipos de signos constitutivos do ritual, segundo uma das tricotomias apresentada por Pierce (1999), qual seja, de que os signos podem ser ícones, índices e símbolos.

3 Utilizo aspas para fazer referência aos termos "descobrimento do Brasil" e "comemoração dos 500 anos" porque eles são ideologicamente situados. São termos utilizados pelo Estado e por outros agentes sociais que carregam valores próprios, os quais procurarei esclarecer ao longo deste texto. Para uma discussão a respeito das ideologias da linguagem, ver Kroskrity (2000).

4 Ideologias a respeito da nação têm sido denominadas de nacionalismo. Para além da existência de diferentes abordagens sobre esse tema (Bendix, 1977; Elias, 1993, 1997; Anderson, 1989; Reis, 1998), está a premissa de que o nacionalismo e a idéia de nação são frutos de configurações históricas e/ou ideológicas particulares.

5 Ao observar as manchetes de jornais de circulação nacional - Jornal do Brasil, Folha de S. Paulo, O Estado de S. Paulo, Correio Braziliense - do dia 23 de abril de 2000, verifica-se a presença de discursos dissonantes, senão opostos, àquele apresentado pelo Estado sobre a história do país no dia anterior. Explorarei algumas das implicações e controvérsias dessas narrativas ao longo do texto.

6 Um índice do estreito vínculo entre a Rede Globo e o Estado pode ser observado nas home pages da presidência da República e do Ministério do Esporte e Turismo. Ambas têm links diretos com a Rede Globo.

7 Discuto de forma mais detida o papel da Rede Globo, pois ele é, nesse sentido, exemplar de como colaboram certos aparelhos ideológicos do Estado (Althusser, 1984) na conformação de ideologias nacionais. Contudo, vários outros atores ligados à mídia e ao marketing estiveram envolvidos na produção desse evento. A sessão "500 anos de Brasil", editada pelo Correio Braziliense aos domingos, durante aproximadamente um ano, também é exemplar. Outros jornais de penetração nacional - Folha de S. Paulo, O Estado de S. Paulo, Jornal do Brasil - lançaram entre janeiro e abril de 2000 vários cadernos dedicados especificamente à discussão do "descobrimento do país".

8 Inspiro-me aqui nas observações metodológicas e empíricas apresentadas por Trouillot (1995) quan- 
do da discussão das estratégias elaboradas pelos Estados e por outros atores sociais para a transformação da chegada de Colombo à América em um fato a ser comemorado em 1892. O autor demonstra que a idéia de comemorar os 400 anos da chegada de Colombo à América só se tornou possível porque se congelaram no tempo e no espaço todos os eventos que antecederam e sucederam a chegada do navegador genovês a este continente em um único dia, silenciando-se a dimensão processual desse acontecimento. Esta é, segundo Trouillot, uma estratégia narrativa que agiliza a transformação de algo que ocorreu naquilo que é dito ter ocorrido. A cristalização do fato histórico o torna, conseqüentemente, mais palatável à memória pública, facilitando a projeção, como produto de entretenimento e turismo, de marcos centenários e suas comemorações.

9 Estes dois instrumentos começaram a ser utilizados pela Rede Globo com dois anos de antecedência ao 22 de abril de 2000.

10 Ao estudar as funções da linguagem, Jakobson (1965) sugeriu a existência de pelo menos cinco delas, além da referencial: função emotiva, quando a ênfase do que é comunicado está na expressão dos sentimentos do emissor; função fática, quando os sinais trocados nos atos de comunicação servem justamente para prolongá-los ou interrompê-los; função conativa, utilizada quando a ênfase da mensagem transmitida está no destinatário; função metalingüística, presente quando o objeto da comunicação versa sobre o código lingüístico em uso; e função poética, quando os princípios de seleção e combinação se arranjam a fim de produzir um efeito estético. Segundo o autor, essas funções não são exclusivas; do ponto de vista empírico, elas se manifestam em conjunto, o que não significa, porém, que não guardem uma relação hierárquica entre si, a qual varia conforme o contexto de enunciação.

11 Ao falar da função metalingüística dos atos de comunicação como aquela na qual se definem os códigos utilizados neste ato, faço referência não somente aos signos lingüísticos, mas também aos padrões morais de cognição (Tambiah 1985, p. 139).

12 Nas comemorações do V Centenário da América houve disputas sobre quais termos seriam mais adequados para descrever a chegada de Colombo ao continente. O termo "encontro" foi escolhido, pois atribuía status de sujeito tanto às populações pré-colombianas, como aos europeus que aqui aportaram. Segundo Touillot (1995), ocorreu um fenômeno distinto por ocasião das comemorações dos "400 anos da Descoberta da América". Nesse período, não houve polêmica em torno do termo "descobrimento".

13 Ver em Oliveira (2000, p. 195), exemplos dessas apresentações: "em abril de 1998, o show de lançamento do Brasil 500 em São Paulo; em julho de 1998, o show Coração Brasileiro em Paris, durante a Copa do Mundo; [...] em outubro de 1998 e de 1999 os shows Criança Esperança em São Paulo, e em dezembro/janeiro os reveillons no Rio de Janeiro; em fevereiro de 1999, os 450 anos de Salvador; em maio de 1999, o show Mama África em Salvador [...] [e por fim] o megashow [...] na Esplanada dos Ministérios em Brasília em 22 de abril de 2000".

14 A fim de elaborar e organizar as atividades a serem desenvolvidas pelo Estado foi criada a Comissão Nacional para as Comemorações do V Centenário do Descobrimento do Brasil (CNVC), por decreto de 12 de maio de 1993. A comissão começou a funcionar de fato em 1997, sob a presidência do Ministério das Relações Exteriores. Segundo Oliveira (2000, p.192), um dos objetivos da CNVC era integrar iniciativas de diferentes órgãos de Estado e da sociedade civil que fariam parte da agenda oficial de comemoração. Um ano antes da execução dos festejos, a coordenação da CNVC foi transferida para o Ministério do Esporte e do Turismo (MET) e a Comissão foi substituída por um Comitê Executivo composto pelos ministros do Esporte e Turismo, Rafael Greca, da Cultura, Francisco Weffort, e pelo secretário geral do Ministério das Relações Exteriores, Luís Felipe Seixas Corrêa, e Andrea Matarazzo, da Secretaria de Comunicação Social da Presidência da República.

15 Cheguei à home page Terra Brasilis através do link existente na página do Ministério do Esporte e Turismo (MET).

16 Segundo o MET, os investimentos do governo federal nessa região foram feitos com o objetivo de "[...] devolver à população e ao Brasil a área dentro das semelhanças mais próximas possíveis do ambiente histórico do descobrimento [...]" (http:///www.met. gov.br/500anos/museu.htm).

17 As atividades direcionadas aos Pataxó deram origem ao Parque Nacional da Coroa Vermelha, "peça" constitutiva do Museu Aberto do Descobrimento.

18 É importante destacar aqui que os Pataxó tiveram um papel ativo nessa transformação. Para uma discussão a respeito das estratégias que vêm sendo adotadas por esse grupo, ver Grünewald (2000).

19 É importante sublinhar aqui que as atividades de construção do MADE incluíram também o plantio de espécies nativas, como o Pau Brasil, em toda a 
"Costa do Descobrimento", numa tentativa de reconstruir o meio ambiente que se imagina ter existido à época da chegada dos portugueses.

20 Locução, ilocução e perlocução são qualidades de determinados enunciados tal como classificados por Austin (1999). Locução é um tipo de enunciado com qualidade referencial; ilocução é um tipo de enunciado que, se proferido em condições adequadas, faz algo ao mesmo tempo em que a sentença é anunciada. Austin denomina esse último tipo de sentença de performative utterances. Por fim, as sentenças perlocucionárias são aquelas das quais se obtém efeitos que não estavam previstos no ato de fala.

21 O mercado editorial e as universidades também tiveram uma participação ativa nesse sentido. Em uma rápida visita a uma das filiais da rede Siciliano, em Brasília, pude identificar a existência de pelo menos dez títulos que faziam referência direta ao fenômeno do "descobrimento". A USP e a UnB, por exemplo, desenvolveram agendas específicas de eventos que tematizavam a questão dos "500 anos". Não quero dizer, contudo, que essas instituições operaram as mesmas conexões semânticas que deram sentido à retórica do Estado; aponto, simplesmente, que foram atores que contribuíram para que a data fosse lembrada publicamente. Quando da comemoração do IV Centenário da Chegada de Cabral ao Brasil, outras instituições similares também contribuíram na mesma direção. Para uma análise de como se deu esse processo na virada do século XIX para o XX, ver Oliveira (2000).

22 O perfil dos eventos que constituíram a agenda oficial de comemorações foi definido no interior do MET, pelo Comitê Executivo da CNVC.

23 Analiso o conteúdo dessas home pages conforme estavam dispostos em dezembro de 2000, período em que pesquisa foi realizada.

24 Destacam-se como exemplos dessa matriz temática os eventos: Encontro Jurídico Internacional sobre a Organização Judiciária e Sistema Processual dos Países de Língua Portuguesa; Parada Naval e Chegada da Regata Histórica, vinda de Lisboa a Porto Seguro; Exposição "Patrimônio Arquitetônico LusoBrasileiro" e Exposição "Moedas Portuguesas da Época do Descobrimento”.

25 Sobre a questão esportiva, fizeram parte da agenda oficial eventos como Taça Brasil 500 Anos: Vasco X Flamengo; Inauguração do Museu do Futebol, no Maracanã; Taça dos 500 Anos, com jogos da seleção brasileira contra seleções de países considerados formadores do povo brasileiro; entre outros.
Sobre a questão relativa ao tema "desenvolvimento”, temos o seminário Redescoberta 2000: A Sociedade do Conhecimento na Língua Portuguesa; inauguração do Centro de Convenções de Porto Seguro; congresso Brasil-Portugal: Meio Ambiente e Desenvolvimento, e Feira Internacional de Hannover, com exposição dos projetos de desenvolvimento sustentável.

26 Em relação à Igreja Católica, receberam, entre outros, a marca de evento oficial: Celebração de missa comemorativa ao aniversário de 500 anos da primeira missa rezada no Brasil, em Santa Cruz da Cabrália; Assembléia Anual da CNBB e missas em ação de graças à "descoberta do Brasil", realizadas em cidades européias. Por fim, a temática diversidade artística brasileira foi expressiva pela variedade de atividades culturais que obtiveram a marca: recital "Um Toque de Classe", com obras de Villa Lobos; IV Festival Amazonas de Ópera, em Manaus, 2000, com apresentações de obras de Carlos Gomes; Exposição "Niemeyer 500 Anos: Do Abstrato ao Concreto", em Brasília; Semana da Cultura Brasileira, realizada em Paris, entre outros eventos.

27 Associação semântica similar foi proposta à época das "celebrações dos 500 anos da América", em 1992. Colombo tornou-se um herói cristão, na perspectiva dos eventos oficiais que interpretavam a descoberta e a civilização do continente como o resultado histórico da conquista material e espiritual da Europa. Não foi por acaso que a Reunião do Episcopado Latino-Americano tenha ocorrido em Santo Domingo, justamente no período das festas que comemoravam a chegada dos europeus na ilha. No Brasil, vale lembrar, a reunião anual da CNBB (Conferência Nacional dos Bispos do Brasil) em 2000 ocorreu em Porto Seguro, à época das "comemorações do descobrimento”. Para uma análise a respeito das estratégias utilizadas pela Igreja Católica e por alguns Estados nacionais para cristianizar Colombo, ver Montero (1996).

28 Denomino lusotropicalismo os discursos Gilberto Freire a respeito da "forma portuguesa de estar no mundo". Em O mundo que o português criou (1940), o autor caracterizou este "estilo de ser e viver" a partir de traços como a abertura para mobilidade e miscigenação e intenso potencial adaptativo. Essas características são tomadas pelo autor como índices da vocação colonizadora de Portugal.

29 Nesse sentido, é importante atentar para as observações de Trouillot (1995) quanto ao duplo sentido que o termo bistória carrega. Ele faz referência tanto aos fatos ocorridos em um processo histórico, como às narrativas produzidas em torno desses fa- 
tos. Segundo Trouillot, é justamente essa sobreposição que dificulta a percepção de como o poder opera na elaboração do relato histórico.

30 A ânsia por colocar o Brasil a caminho do progresso e da modernidade também esteve presente nos discursos e nas atividades desenvolvidas por ocasião da comemoração do IV Centenário. Nesse momento, celebrou-se os progressos alcançados pelo país na área de engenharia e medicina, no sentido de ressaltar o esforço do Brasil em ingressar na modernidade por meio de reformas urbanas, construção de estradas e luta contra doenças tropicais. Segundo Oliveira (2000, p. 190), "as reformas urbanas e o saneamento constituíram como que uma 'metáfora da reforma social' desejada e serviam para marcar uma ruptura com o passado". Assim, vale lembrar que a então recente instauração da República sofrera forte influência de ideologias positivistas, representadas de forma exemplar pelo lema ordem e progresso, inscrito na bandeira nacional.

31 No discurso de $1^{\circ}$ de janeiro de 2000 , após declarar o vínculo do Brasil com Portugal e a mestiçagem que deu origem ao povo brasileiro, o presidente afirmou: "Nossa economia está entre as cinco que mais cresceram no século e nenhum país dos que andaram depressa se aproxima do número de habitantes que temos. [...] Industrializamo-nos, lançamonos na aventura da Ciência e da Tecnologia. Fabricamos e exportamos aviões, desenvolvemos tecnologias para exploração do petróleo em águas profundas [...]. se contávamos apenas com 16\% de pessoas que sabiam ler e escrever no início do século XX, são menos de 15\% os que, infelizmente, ainda são analfabetos. Quase todas as nossas crianças - 96\% - estão nas escolas [...]”.

32 No Uruguai, à época das comemorações do V Centenário da chegada de Colombo à América, também ocorreram movimentos de protestos similares. A organização Mundo Afro programou contra-festejos do descobrimento da América, sob o slogan "500 años, Ahora Basta!". Os panfletos distribuídos por ocasião desta campanha convocavam os cidadãos para comemorar o 11 de outubro como sendo o último dia da liberdade americana. A esse respeito, ver Ferreira (2000).

33 Em declaração ao Correio Braziliense de 22 de abril de 2000, Marina Silva, então senadora pelo Partido dos Trabalhadores do Acre e participante da marcha Brasil Outros 500, afirmou que "o país não reparou as injustiças históricas cometidas contra os negros, índios e outros excluídos". Em outra ocasião, a senadora declarou: "Tem uma outra versão desses 500 anos que precisa ser reparada. Precisa ser construí- da uma nova forma de relacionamento entre os diferentes segmentos da população brasileira visando à inclusão. É isso que as pessoas estão querendo, reivindicando aqui".

34 Ver, por exemplo, as manchetes de jornais nessa ocasião: "500: festa oficial e protestos de sem-terra e índios marcam hoje o V centenário do Brasil" ( $O$ Globo, 22/4/2000); "Batalha na festa dos 500: sete índios ficam feridos e 140 manifestantes são presos em choques com PMs da Bahia" (O Globo, 23/4/2000); "Confronto na festa dos 500 faz 141 presos" (O Estado de S. Paulo, 23/4/2000); "160 presos, 30 feridos: protestos na festa do descobrimento acaba em demissão do presidente da Funai" (Correio Braziliense, 23/4/2000).

35 No início da organização das comemorações o cerimonial da presidência da República trabalhava com a expectativa de que Fernando Henrique Cardoso ficaria dois dias na região de Porto Seguro, mas diante da possibilidade de protestos sua estadia reduziu-se a apenas quadro horas na região.

36 Para uma análise de outros efeitos perlocucionários dos eventos promovidos pelo Estado nesse período, ver Reppetto (2000) e Vásquez (2000).

37 É importante destacar que a "ética de solidariedade" foi também afirmada pela Rede Globo no âmbito do projeto Brasil 500. Ela foi a pedra angular do projeto Amigos da Escola, que procurou incentivar indivíduos a prestar serviços voluntários em estabelecimentos educacionais públicos.

\section{BIBLIOGRAFIA}

ALTHUSSER, Louis. (1984), Aparelhos ideológicos de Estado. Rio de Janeiro, Graal.

ANDERSON, Benedict. (1989), Nação e consciência nacional. São Paulo, Ática.

AUSTIN, John L. (1999), How to do things with words. Londres, Havard University Press.

BENDIX, Reinhard. (1977), Nation-building and citizenship. Berkeley, University California Press.

CARVALHO, José Murilo. (2000), "Entrevista com José Murilo de Carvalho", in José Geraldo Couto e Leny Cordeiro, Quatro autores em busca do Brasil, Rio de Janeiro, Rocco. 
CHAUí, Marilena. (1994), "Raízes teológicas do populismo no Brasil: teocracia dos dominantes, messianismo dos dominados", in E. Dagnino, Anos 90: política e sociedade no Brasil, São Paulo, Brasiliense.

DAMATTA, Roberto. (1991), A casa \& a rua: espaco, cidadania, mulher e morte no Brasil. Rio de Janeiro, Guanabara/Koogan Ed.

DAS, Venna. (1995), Critical events: an anthropological perspective on contemporary India. Oxford, Oxford University Press.

DUMONT, Louis. (1985), O individualismo. Rio de Janeiro, Rocco.

DUMONT, Louis. (1994), German ideology: from France to Germany and Back. Chicago, The University of Chicago Press.

DURKHEIM, Émile. (1983), Lições de sociologia: a moral, o direito e o Estado. São Paulo, Edusp.

ELIAS, Norbert. (1972), "Processes of state formation and nation building", in Transactions of the seventh world congress of sociology, vol. 3, International Sociological Association, Geneva.

. (1993), O processo civilizador: formação do estado e civilização. Rio de Janeiro, Jorge Zahar.

(1997), Os alemães: a luta pelo poder e a evolução do habitus nos séculos XIX $e X X$. Rio de Janeiro, Jorge Zahar.

FERREIRA, Luis. (2000), "Los '500 años' em Montevideo". Pós - Revista Brasiliense de Pós-Graduação em Ciências Sociais, ano IV, pp. 39-49, Brasília, Instituto de Ciências Sociais da Universidade de Brasília.

FREIRE, Gilberto. (1940), o mundo que o português criou. Rio de Janeiro, Livraria José Olympio Editora.

(1995), Casa grande \& senzala. Rio de Janeiro, Record.

GEERTZ, Clifford. (1989), A interpretação das culturas. Rio de Janeiro, Editora Guanabara.
GLUCKMAN, Max. (1963), Custom and conflict in Africa. Oxford, Blackwell Publishers.

GRÜNEWALD, R. A. (2000), Os Pataxó e o turismo no litoral sul baiano. Comunicação oral apresentada na XXI Reunião da ABA, Brasília.

HERSCHMANN, Micael \& PEREIRA, Carlos Alberto Messeder. (2000), "E la nave va... As celebrações dos 500 anos no Brasil: afirmações e disputas no espaço simbólico". Estudos Históricos, 26: 203-215.

HOLANDA, Sérgio. B. de (1982), Raizes do Brasil. Rio de Janeiro, José Olympio.

JAKOBSON, Roman. (1965), Lingüistica e comunicação. São Paulo, Cultrix.

KROSKRITY, Paul. (2000), Regimes of languages: ideologies, polities and identities. School of American Research Press.

MONTERO, Paula. (1996), "A universalidade da Missão e a particularidade das culturas", in __ (org.), Entre o mito e a bistória: o V Centenário do Descobrimento da América, Petrópolis, Vozes.

MONTERO, Paula \& THOMAZ, Omar. (1996), "O palácio de cristal", in Paula Motero (org.), Entre o mito e a história: o V Centenário do Descobrimento da América, Petrópolis, Vozes.

OLIVEIRA, Lúcia Lippi. (2000), "Imaginário histórico e poder cultural: as comemorações do Descobrimento". Estudos Históricos, 26: 183-202.

PIERCE, Charles. (1999), Semiótica. São Paulo, Perspectiva.

RAMOS, Alcida Rita. (2001), Rediscovering indigenous Brazil: echoes from the Quincentennial. Série Antropologia, 296, Departamento de Antropologia da Universidade de Brasília.

REIS, Elisa. (1998), Processos e escolhas: estudos de sociologia politica. Rio de Janeiro, Contra Capa. 
REPETTO, Maxim. (2000), "Conferência dos povos e organizações indígenas/2000". Pós - Revista Brasiliense de Pós-Graduação em Ciências Sociais, ano IV, 2000, pp. 39-49, Brasília, Instituto de Ciências Sociais da Universidade de Brasília.

SILVA, Kelly. C. (2000), O novo nome da democracia: a retórica sobre os direitos bumanos no governo Fernando Henrique Cardoso. Dissertação de mestrado, Brasília, UnB.

TAMBIAH, Stanley. (1985), "A performative approach to ritual", in D. J. Tambiah, Culture, thought and social action, Londres, Havard University Press.

. "Form and meaning of magical acts", in D. J. Tambiah, Culture, thought and social action, Londres, Havard University Press.

THOMAZ, Omar \& LICHTENTHÄLER, Waldenir. (1996), "O mundo que o português criou", in Paula Motero (org.), Entre o mito e a história: o $V$ Centenário do Descobrimento da América, Petrópolis, Vozes.

TROUILLOT, Michel-Polph. (1995), Silencing the past: power and the production of history. Boston, Beacon Press.

TURNER, Victor. (1957), Schism and continuity in a African society: a study of Ndembu village life. Manchester, Manchester University Press.

. (1972), The drums of affliction. Oxford, Clarendon Press/Oxford University Press.

VÁSQUEZ, Ladislao Landa. (2000), "Los indígenas y los 500 años de Brasil". Pós - Revista Brasiliense de Pós-Graduação em Ciências Sociais, ano IV, pp. 39-49, Brasília, Instituto de Ciências Sociais da Universidade de Brasília.

\section{Fontes primárias}

\section{Home Pages}

www.presidencia.gov.br/500.htm - Acesso em dezembro de 2000.

www.met.gov.br/500anos - Acesso em dezembro de 2000 .

www.radiobrás.gov.br/abrn/integras/99 - Acesso em dezembro de 2000.

www.500anos.com.br/porto.htm - Acesso em dezembro de 2000.

\section{Vídeo}

Terra à vista. (2000), produção de Manoel Martines e Marcelo Aguiar, Brasília, Universidade Católica de Brasília. Fita de Vídeo (20 minutos), VHS, son., color. 


\section{A NAÇÃO CORDIAL: UMA ANÁLISE DOS RITUAIS E DAS IDEOLOGIAS OFICIAIS DE "COMEMORAÇÃO DOS 500 ANOS DO BRASIL"}

Kelly Cristiane da Silva

\section{Palavras-chave}

Ritual; 500 anos do Brasil; Retóricas de integração nacional; Antropologia da política.

Este artigo analisa os eventos promovidos pelo Estado brasileiro para celebrar aquilo que, entre os anos de 1998 e 2000, foi por ele denominado de "500 anos de descobrimento do Brasil". A autora faz um mapeamento das ideologias afirmadas nessas atividades, revelando as imagens de nação decorrentes delas. Mostra, ainda, que essas atividades representam momentos críticos do processo de nation-building brasileiro. A partir da análise de documentos, discursos, exposições e eventos, a autora sugere que os rituais performatizados por ocasião dos festejos retomam a fábula das três raças e um certo ideal lusotropical, abrindo espaço para a reedição da idéia de democracia racial por parte do Estado.

\section{THE CORDIAL NATION: AN ANALYSIS OF RITUALS AND OFFICIAL IDEOLOGIES OF THE "500 YEARS OF BRAZIL CELEBRATION"}

Kelly Cristiane da Silva

\section{Keywords}

Ritual Brazilian 500 years; Nationbuilding discourses; Anthropology of politics.

This paper discusses the events organized by Brazilian State to celebrate the so called "500 years of Brazil's discovery", between 1998 and 2000. It seeks to identify the ideologies found in these activities, which revealed the images of the nation. It shows that those activities were critical events for the Brazilian nationbuilding process. Taking for analysis documents, discourses, exhibitions, museums, and others, the paper suggests the rituals performed at those "celebrations" retake the Brazilian myth of the "three races" and a kind of lusotropicalist ideal, making possible the reediting of the idea of a "racial democracy" by Brazilian State.

\section{LA NATION CORDIALE: UNE ANALYSE DES RITES ET DES IDÉOLOGIES OFFICIELLES DE COMMÉMORATION DES 500 ANS DU BRÉSIL"}

\author{
Kelly Cristiane da Silva
}

\section{Mots-clés}

Rituel; 500 ans du Brésil; Rhétorique de l'intégration nationale; Anthropologie de la politique.

L'article analyse les festivités organisées par l'État brésilien pour célébrer ce qui a été appelé, au cours des années 1998 et 2000, les "500 ans de la découverte du Brésil”. Il cherche à identifier les idéologies présentées par ces festivités, en révélant les images de la nation qui lui donnent corps. L'auteur présume que ces activités sont des moments critiques pour le processus de nation-building brésilien. À partir de l'analyse des documents, des discours, des expositions, des musées et autres, l'auteur suggère que les rituels mis en place pendant ces célébrations reprennent le mythe brésilien des "trois races" et un certain idéal lusotropical, ouvrant les portes pour une réédition de l'idée de la "démocratie raciale" par l'État. 